\title{
You Live and You Learn
}

\section{JaiAnna Megahan}

I was only nineteen when I danced with the Grim Reaper.

Prior to being a student at UTA, I was at University of Houston. It was close enough to home that my parents could come down if something happened, but far enough away that I felt I could focus on who I was outside of the family home.

My first semester at college, I made friends with a very diverse group of people. We were this beautifully dysfunctional family that stuck with each other through the good times and the bad. Especially the bad.

My friends helped me decide to start taking birth control. "You would rather have it and not need it than need it and not have it, right?" It made sense enough to me although history never expressed a need for it, so I "got on the pill."

After a fun semester focusing on my new friends, breaking records in the bowling alley, all-nighters during exam weeks, and midnight snacks at our 24-hour dining hall, I began feeling under the weather. I noticed it slowly over the start of the second semester. I couldn't run as fast during our weekly basketball games because my heart would race more than usual. I would start coughing out of nowhere, barely able to stop once I started. Then I noticed that I would start panting just from changing my clothes or leisurely walking to my class. I had this intense, unfamiliar pain in my calves. Me being me and how I was raised, I worked through the pain because I thought it was all in my head. In fact, I thought that everything I was experiencing just meant that I was more out of shape than I realized, so I decided to push myself harder in the gym.

However, one day I was walking to my dorm and my mom heard how out of breath I was. "JaiAnna, that isn't normal, and you need to go to the campus clinic as soon as possible."

The nurse practitioner was very intrigued by everything I was feeling and seemed to already come to a secret diagnosis. She sent me on my way with an inhaler, some antibiotics, and told me to come see her at the end of the week for a follow-up. She said to pay close attention to how the pain in my calves felt as time went by.

On February 15th, it was time for my follow-up appointment. As I was walking to the clinic, every step felt like someone was taking a steak knife and going at my calf like a ribeye. I was incredibly out of breath by the time I made it and mentally making plans to ice my leg and hit the gym the next day to continue getting myself in shape. When I walked in the examination room, she didn't waste time with initial greetings. "How are your legs feeling? Is it any different from when you came in at the beginning of the week?" When I told her the pain was localized to just my right calf, she looked at me like my head was becoming a headstone. She asked me if I was on birth control, and when I said yes she told me she was sending me to get an emergent ultrasound.




"I think you have a blood clot in your leg."

The feeling of dread that bubbled in my stomach and sent my mind spiraling was a feeling I'll never forget.

My head was spinning with so many thoughts that my mouth didn't know which one to pick. My entire body disguised itself in goosebumps as I left her office in a daze.

The journey from her office to the imaging center was filled with muffled tears in the back of an Uber. I remember the driver saying words but not being able to process them.

The imaging center had the lighting of every Harry Potter film: dim. It was as if no happiness resided there. And for good reason.

The technician and radiologist shared bewildered stares between each other with hushed whispers to match as they went over my results. They didn't include me in their conversation. They didn't realize that I needed to be a part of that conversation. Instead I was just given orders and a CD.

"You need to go to a hospital immediately. You have a very large blood clot in your right leg."

Honestly, I didn't really know what this meant. I was only nineteen years old. I wasn't a doctor. I was only a freshman pre-med student. I didn't even know what questions to ask.

They didn't explain what this meant. They didn't tell me why this was bad. They just sent me on my way and moved on to the next patient as if I knew what to do.

My friend Robin met me at the hospital to wait with me until my family arrived. We were unknowingly sitting in a trauma hospital. I thought my leg, being four times the size it was normally, was traumatic. Well, it was for me. It wasn't so much for them.

Four hours passed when my family arrived from Dallas and switched shifts with Robin. My mom gave them another two until she decided her child wasn't going to be waiting any longer without at least the possibility of being seen. We ended up going to this triage center that was separate from its parent hospital.

In that triage center I saw five doctors.

The first one took my vitals and sent me back into the lobby.

The second one took me to get a CAT scan with a contrast that made you feel like you were peeing yourself.

After that I was rolled away to a room where another doctor took a second ultrasound from my ankle up to my hips. 
The fourth doctor was my absolute favorite. He had been given the results of my ultrasound that showed I didn't have a blood clot in my calf. He tried to explain to my mother and me (two black women), in the most condescending way, that I had only pulled a muscle. He dumbed down his explanation the way an adult tries to explain the mechanics of a clock to a child. However, he spoke to my father (a white man) in a more scientific way. He used medical terminology and spoke the way two adults of academia speak to each other.

That was the first time I had ever experienced a white doctor casting aside what a black patient was feeling and dumbing down the results to fit the stereotype he already had for us.

The fifth doctor, I assumed he was a radiologist, escorted the fourth out of the room to discuss the results of my CAT scan. Then the same doctor who was trying to write off my symptoms as omething as common as a pulled muscle came bursting into the room, smiling from ear to ear.

"We found the clot! It dislodged and went in your lungs! Actually, there are a lot of them in your lungs! We are going to have an ambulance come get you and take you to our primary hospital location so you can be admitted and treated accordingly!"

He acted as if he had won the lottery, not thinking about how his excitement would affect my parents. Or me.

I hadn't even noticed my tear-stained hospital gown until my mom was reassuring me that everything was going to be okay.

Everything was happening to me.

Everyone was speaking at me.

I was engulfed with anxiety, and no one was giving me time to just breathe.

It was well past midnight by the time we arrived at our last destination. The night doctors, in my personal opinion and experience with them over the next week, did not care as much as the doctors in the daytime. I was more of an inconvenience to them than a teenager who just had their world turned upside down.

\section{Peverything was happening to me Everyone was speaking at me99}

Before I could attempt to get a couple of hours of sleep, my doctor and nurse had a very vocal fight about starting me on a heparin (blood thinner) drip. My nurse fought hard for me to be put on it because she believed it would make sure I got through the night. Luckily for me, she won the fight, and I honestly can't thank her enough.




I spent a week in that hospital surrounded by doctors and nurses saying things like, "It's a miracle you're alive," "We call pulmonary embolisms the silent killer," and "If you hadn't have come in tonight you probably would've died in your sleep." My mother had to ask the doctor to explain what was happening to me. She had to ask them to tell me how the clot in my leg basically swam up my vein, went through my heart, and decided to make a home within my lungs. Then they told me that this clot actually saved my life because "my lungs were covered with so many clots they couldn't count them" and the clot in my leg helped bring attention to a far more worrisome problem. I even learned that I have a clotting factor that puts me more at risk than others to develop blood clots.

That entire week I felt like a limited time only museum exhibit that everyone had a ticket to.

Everyone but me.

I had never felt more alone, more confused, more frightened, than I did in that week in the hospital.

But I lived.

But not only did I live, I learned.

When you go through school as an aspiring physician, you are taught techniques, theories, and told to see the body as a machine. You are the mechanic looking for what caused the car to breakdown, pulling out the tools you need, and fixing it up quickly so you can get to the next one.

However, that week in the hospital allowed me to experience medicine as a patient.

I wasn't a broken machine that needed to be sent down an assembly line to fix before heading to the next one.

I wasn't the individual body part or condition that brought me to the hospital.

I was a human being.

I had emotions and feelings that weren't being seen.

I was scared, confused, anxious, sad, angry, and everything in between.

But most importantly, I was vulnerable.

I came in not knowing what was happening to me, not being told anything, but trusting multiple doctors to take complete control over my body and care for me. Giving in to having no control or no say because I trusted them to help heal me and help me understand what was going on.

This feeling of basically being helpless isn't something you can read in a textbook.

As a future physician, I want to create a more humane medical practice. This has been a hot topic for a very long time within the medical field. It is known and discussed that doctors aren't always the most empathetic professionals you'll come across. We are striving to bring the knowledge of medical humanities into the healthcare profession. However, the best lesson I learned about how to be the doctor I aspire to be was by being the patient I aspire to treat. The saying "Before you judge a man, walk a mile in his shoes" is what we should keep in mind as we are entrusted with patient's lives and feelings.

The majority of students go into the medical field to help people. We can only go so far with the technical information that we learn in the classroom. We must learn the science, practice the compassion, and teach both.

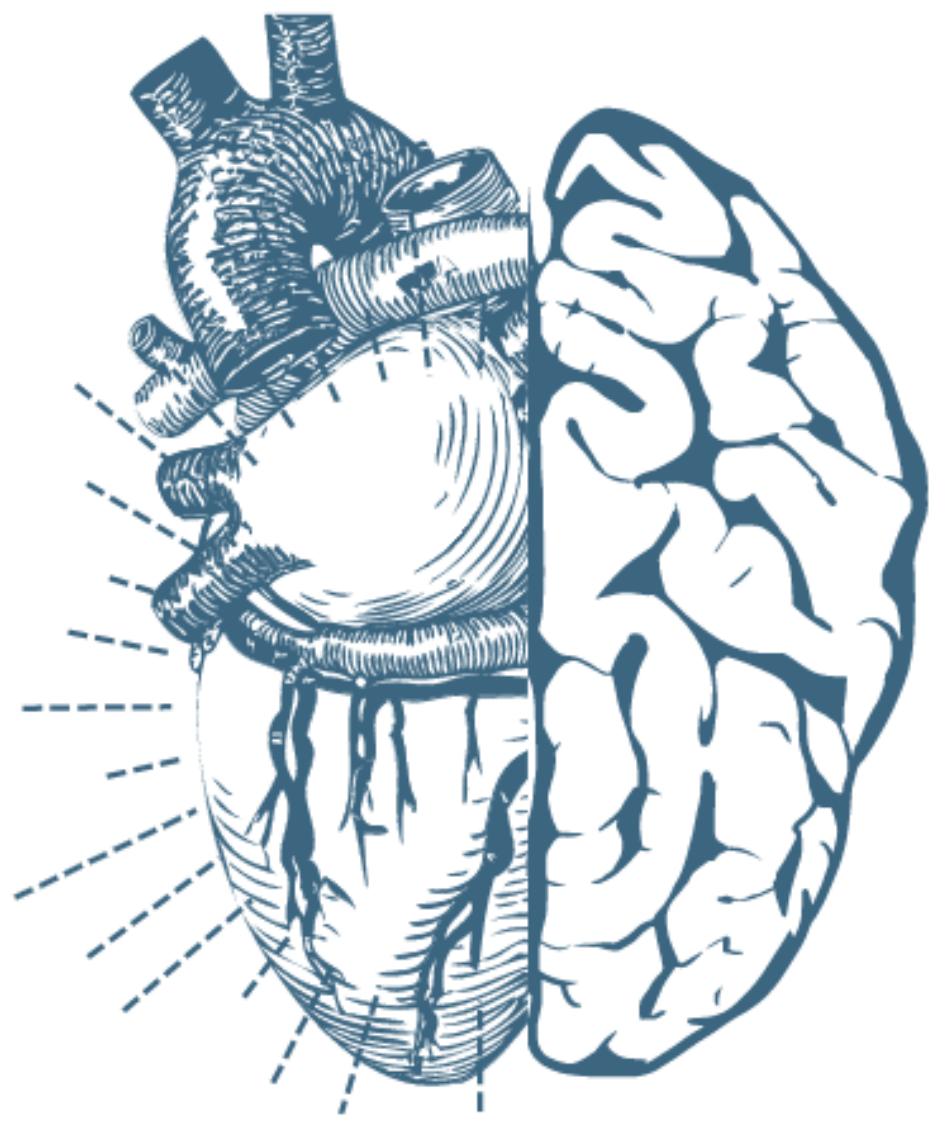

